\title{
The contribution of the middle cerebral artery and callosal artery to the vascularisation of the Facies convexa of the brain in horses with reference to the equine-specific cartographic pattern of the neopallium
}

\author{
L. Böing, F. Heun, H. Gasse \\ Institute of Anatomy, University of Veterinary Medicine Hannover, Germany
}

[Received: 7 April 2020; Accepted: 25 May 2020]

Background: The extremely complex surface architecture of the equine brain does not allow a uniform transfer of anatomical data from other mammalian species, e.g., dog or cat. Rather, a special approach is required to elucidate the equine-specific patterns of cerebral vascular ramifications. Therefore, a novel cartographic system was applied. Prior attention was paid to the A. cerebri media (MCA) and to the A. corporis callosi (CA), as they spread over the widest part of the neopallium's Facies convexa (i.e. the lateral and dorsal surface), thus being of particular interest in terms of surgical treatment of trauma of the skull and brain. Materials and methods: The brains of 17 adult warmblood horses were studied. The neopallium's Facies convexa was subdivided into 15 sectors clearly delineated by the primary sulci and by related auxiliary lines. The courses and destinations of main branches (= branches of $1^{\text {st }}$ or $2^{\text {nd }}$ order, with a minimum calibre of $0.75 \mathrm{~mm}$ ) of MCA and CA were topographically analysed by means of superimposed graphical sketches.

Results: The MCA had six main branches (numbered in rostrocaudal direction); the CA had seven main branches. The main branches of the MCA spread over the widest part of the Facies convexa, but never reached the rostral pole and the caudal pole of the neopallium. Clearly, the main branches of CA proceeded from the hemisphere's medial side across the Margo dorsalis cerebri, thus supplying rostrodorsal and dorsal sectors of the Facies convexa.

Conclusions: The topographical analysis of the vascular ramification patterns (regions of residence) in combination with the cartographic system of sectors of the neopallium respected the equine-specific surface architecture. It highlighted the distinct vascular supply areas and the particular multiple-supply situations especially in sectors presumably related to the equine area motorica. (Folia Morphol 2021; 80, 2: 237-247)

Key words: horse, brain cartography, cerebrum, gyration, middle cerebral artery, callosal artery, ramification pattern

Address for correspondence: Dr. L. Böing, Institute of Anatomy, University of Veterinary Medicine Hannover, Bischofsholer Damm 15, D-30173 Hannover, Germany, tel: +49 511856 7484, e-mail: lucien.boeing@tiho-hannover.de; hagen.gasse@tiho-hannover.de 


\section{INTRODUCTION}

The presence of several arterial branches supplying the brain hemispheres of horses was reported $[1,17$, 24]. However, their further courses, positions and local distributions on the neopallium have not been described in detail. The same is true for the current sixth edition of the Nomina Anatomica Veterinaria [25] and the corresponding illustrated edition [5]: They list the cerebral stem arteries (e.g., A. cerebri media [MCA] on the brain's basolateral surface). However, they fail to display the individual branches originating from them and, for example, continuing along the neopallium's lateral and dorsal surface (i.e. Facies convexa).

Such a topographical description of a general vascularisation pattern of the equine cerebral hemispheres is challenged by the special surface architecture of the equine neopallium $[2,12]$. In horses, the gyration pattern is complex [21, 23] due to the varying arrangements of the plentiful secondary sulci. A typical bow-like conformation of the gyri ("Bogenwindungen"), like in carnivores, does not exist in horses $[1,8$, $20,21]$. Despite this, the significance of the primary sulci of the equine neopallium has been highlighted [21], as they occur regularly and can be used as the key features for a topographical orientation. However, the space between them is too wide (and the secondary sulci in between are too irregular) to allow an adequate topographical reference to certain sites of smaller dimensions. Consequently, a new cartographic system of orientation $[3,13]$ was introduced. It refers to the primary sulci [21] and to related auxiliary lines $[3,13]$, dividing the neopallium's surface into $21 \mathrm{sec}-$ tors ( 15 of them on the lateral Facies convexa).

The aim of this study was to describe in appropriate detail the ramifications of the MCA and A. corporis callosi (CA). In particular, special attention was given to the neopallium's sectors to elucidate whether there was a basic ramification pattern and if specific vascular supply areas existed.

\section{MATERIALS AND METHODS}

The heads of 17 adult, warmblood horses were fixed by perfusion with $10 \%$ formalin ( $10 \mathrm{~L}$ on average) via the left $A$. carotis communis (the left and right $V$. jugularis externa were cut; however, the right A. carotis communis was clamped in order to prevent early reflux of the fixative). Five of the heads were subsequently injected with $60 \%$ latex milk via the same port. The cerebral hemispheres were macroscopically dissected ex situ.
The horses had been purchased from local animal trade companies to be used as specimens in the anatomical dissection classes of the University of Veterinary Medicine Hannover, Germany. They had been euthanased either prior to or immediately after their arrival, without being housed at the institute's facilities. All related procedures were carried out in accordance with the German Federal Law, that is the Protection of Animals Act (Tierschutzgesetz §4, §7, §7a) as well as the Directive of the European Parliament and of the Council for the Protection of Animals Used for Experimental and other Scientific Purposes (2010/63/ /EU). Accordingly (Tierschutzgesetz §7), no explicit permission to conduct this study was necessary because no medical procedures or experiments were carried out while the animals were alive, except intravenous injection for euthanasia. Euthanasia was carried out by qualified and authorized medical staff by means of an initial general anaesthesia by $2 \%$ isoflurane (Isofluran CP $1 \mathrm{~mL} / \mathrm{mL}$, CP-Pharma Handelsgesellschaft $\mathrm{mbH}$, Burgdorf, Germany) and consecutively administering $60 \mathrm{mg} / \mathrm{kg}$ pentobarbital i.v. (Euthadorm ${ }^{\circledast} 400 \mathrm{mg} / \mathrm{mL}$, CP-Pharma Handelsgesellschaft mbH, Burgdorf, Germany). This procedure was approved by the University's Animal Welfare Officer, confirmation TVO-2018-V-71.

The hemisphere's Facies convexa was subdivided in accordance with the previously described method $[2,12]$. In this cartographic approach, firstly, the primary sulci [21] were the essential key landmarks (Fig. 1). Secondly, six points of orientation (PO-1 to PO-6) - all related to the aforementioned primary sulci - were marked on the Facies convexa of the neopallium (Fig. 1). Finally, auxiliary lines - oriented to these points of orientation - completed the division into 15 lateral and dorsal sectors (Fig. 1; red dotted lines).

Branches directly originating from the MCA or CA, i.e., branches of $1^{\text {st }}$ order, were dissected together with those subsequently deriving from them, i.e., branches of $2^{\text {nd }}$ order. Both categories of branches had a minimum width of $0.75 \mathrm{~mm}$ and were designated as the main branches. Further and smaller branches originating from these main branches were discriminated. The identified main branches were numbered in a rostrocaudal direction (i.e., main branch 1 was the most rostral one).

Standardised photographs $\left(90^{\circ}\right.$ perspective, in lateral and medial view) were used to draw sketches of the individual arterial ramifications. These sketches were digitally superimposed in one graphical rep- 


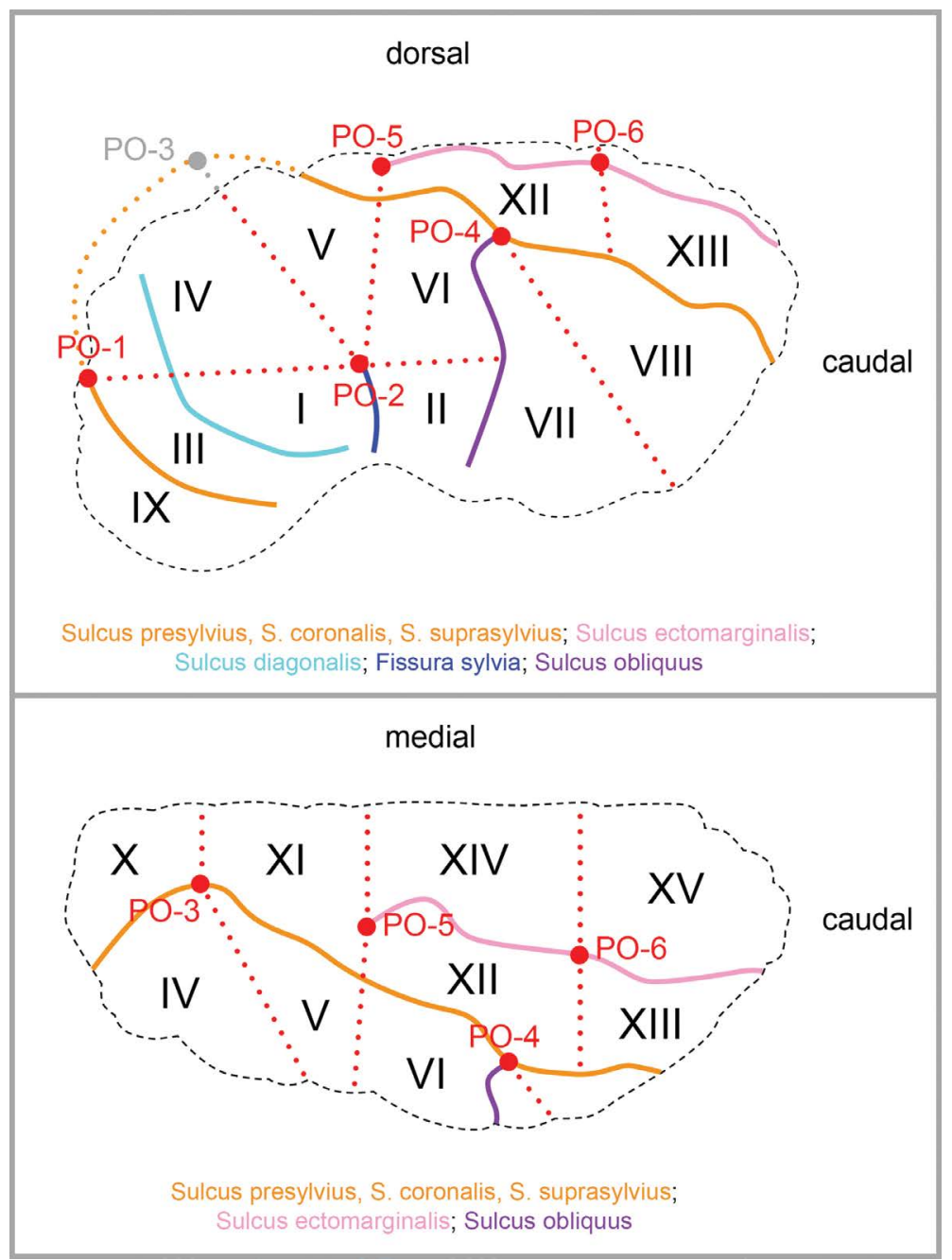

Figure 1. Graphical illustrations of the sectors I to XV located on the Facies convexa of the neopallium (top: lateral view; bottom: dorsal view). The coloured primary sulci [21] were topographically related to six points of orientation ( $\mathrm{PO}-1$ to $\mathrm{P0}-6$ ) that were used to place auxiliary lines (red dotted). The latter divide the spaces between the primary sulci into the sectors. The numbering of the sectors always starts rostral (sector I) and caudal (sector II) to the Fissura sylvia, continuing thereafter in a concentric, bow-like manner. In the strictly lateral view (figure on top), parts of the sulcus coronalis (yellow dotted lines), and the P0-3 (grey) and sectors X, XI, XIV and XV are not visible. P0-1: Most rostral point on the continuation of sulcus presylvius, sulcus coronalis and sulcus suprasylvius; PO-2: Dorsal end of Fissura sylvia; PO-3: Most medial point on the continuation of sulcus presylvius, sulcus coronalis and sulcus suprasylvius; $\mathrm{P0}-4$ : Connection of sulcus obliquus with sulcus suprasylvius; P0-5: Rostral end of sulcus ectomarginalis; PO-6: Half way on sulcus ectomarginalis; the auxiliary line connected to PO-4 cuts the space between sulcus obliquus and sulcus suprasylvius into two parts of same size; the auxiliary line cutting P0-6 is connected orthogonally to the Margo dorsalis cerebri ("Mantelkante"); further auxiliary lines start at PO-1, PO-3 and PO-5, respectively, and are connected orthogonally to the Margo dorsalis cerebri.

resentation in order to highlight similarities in terms of a basic pattern of ramification. Furthermore, the sketches helped to display individual variations in the ramifications and courses of the respective blood vessels, i.e., their local distributions related to the neopallium's sectors.

The brain hemispheres slightly differed in size; this discrepancy was adjusted by proportional graphical scaling of the neopalliums' outlines. This procedure revealed that all of the brains had similar proportional dimensions because the contours of the superimposed, individual sketches varied only slightly. Consequently, a mean contour was used in further illustrations.

\section{RESULTS}

\section{Origin and ramification of MCA}

The A. cerebri media originated (in 16 of 17 brains) from the $A$. cerebri rostralis (RCA) that represented the rostrolateral part of the circulus arteriosus cerebri (CAC). The MCA lay directly rostral to the lobus prirformis; in some specimens, it took an initial, slightly curved, rostral course, in others, it ran almost verti- 


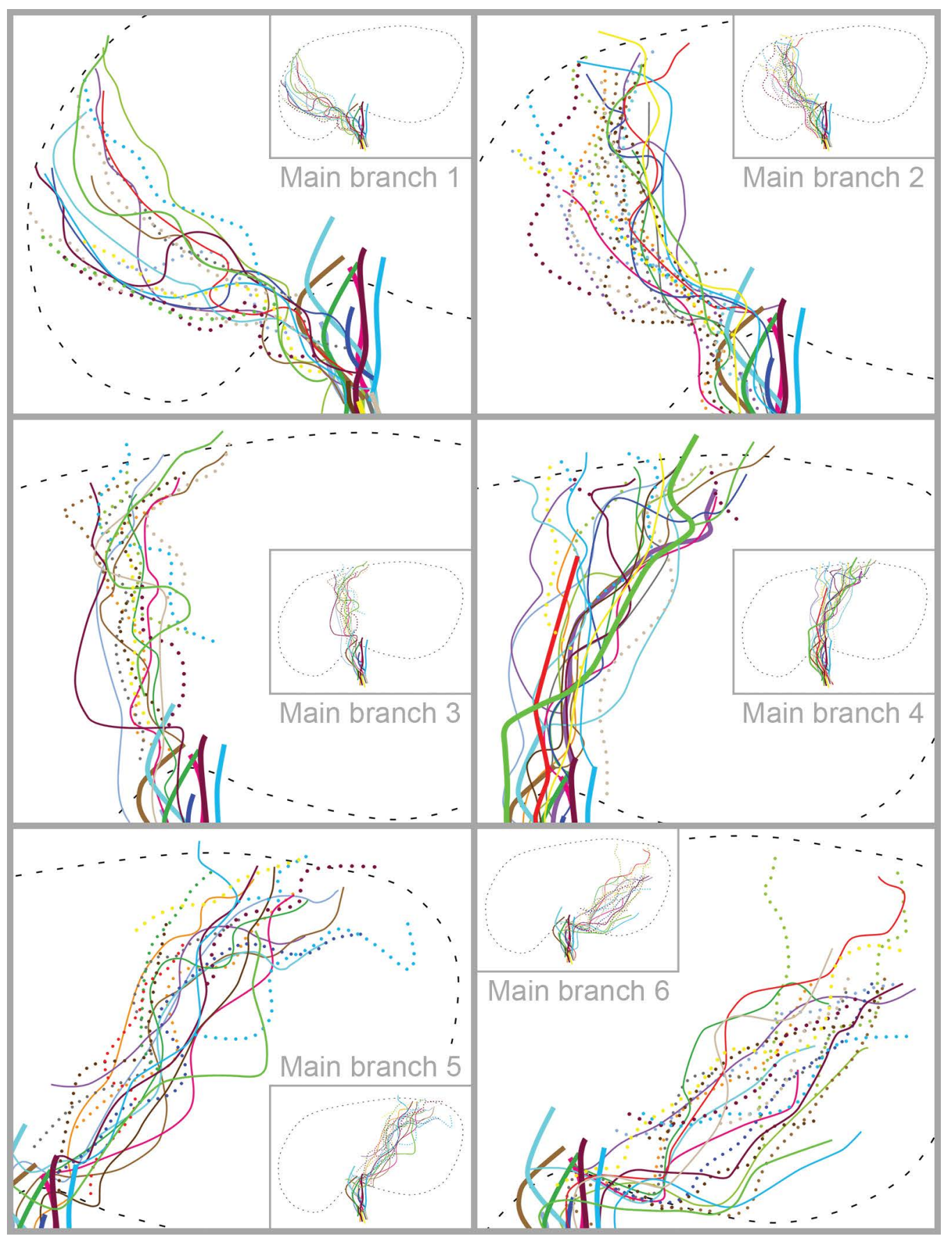

Figure 2. Graphical representations of the A. cerebri media (MCA; thick lines), and its six main branches. The comparative survey was facilitated by means of superimposition of the 17 sketches from the 17 equine brains (colour-coded). The main branches were of $1^{\text {st }}$ order (thin lines) or of $2^{\text {nd }}$ order (dotted lines). Lateral view $\left(90^{\circ}\right.$ perspective); the neopallium is delineated by a mean contour (dashed line). Each of the main branches 1 to 6 spread over its typical region of residence (Note: When the MCA did not bifurcate, it ran far into the dorsal direction and was designated as the main branch 4).

cally in a dorsal direction. Finally, the MCA reached the neopallium in the region of the Fissura sylvia, i.e., between the ventral parts of sectors I and II. In one brain, there was no rostrolateral portion of a CAC due to the lack of a left RCA. In this single case, the left MCA represented the rostral branch of the left A. carotis interna (ICA).
Six main branches originated from the MCA (Fig. 2). Three of them were present in all brains (main branches 2, 4 and 6); the other main branches were found in $76-88 \%$ of the cases. Some of the main branches occurred double or three-fold in some brains; this applied to main branch 3 in $23 \%$ of the brains, and to main branches 2 and 4 in $41 \%$ of the brains. 


\section{Basic ramification pattern}

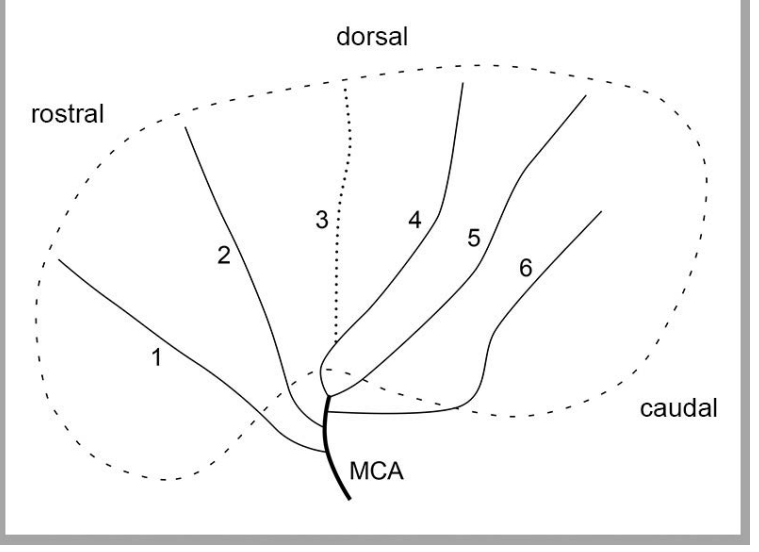

Figure 3. Sketch of a proposed basic pattern of ramification of the A. cerebri media (MCA) into six main branches; all of them were predominantly of $1^{\text {st }}$ order, except main branch 3 , which was mainly of $2^{\text {nd }}$ order (dotted line). Note the bifurcation into main branches 4 and 5. Meandering courses are not displayed; approximate position on the neopallium according to Figure 2. Lateral view; dashed line - mean contour of the neopallium.

A bifurcation of the MCA was present in almost all of the brains (82\%). Such a bifurcation was predominantly located slightly ventral to the sulcus rhinalis lateralis and rostral to the lobus piriformis (i.e., ventral to the region of the Fissura sylvia). The arms of this bifurcation (Fig. 3) were represented by main branch 4 (in $93 \%$ of the cases) and main branch 5 (in 58\% of the cases). However, in a few brains (3 of the 17), no such bifurcation of the MCA was found at all. In those cases, the non-bifurcated MCA continued far, towards the neopallium's Margo dorsalis, and represented main branch 4 (Fig. 2).

The main branches originated directly from the MCA (except main branch 3) and, hence, were branches of 1 st order (Figs. 2, 3). Only main branch 3 was an exception; it either ramified directly from the MCA as a branch of $1^{\text {st }}$ order (in $40 \%$ of cases), or it represented a branch of $2^{\text {nd }}$ order deriving from main branch 4 (in $40 \%$ of the cases), or it was a branch of $2^{\text {nd }}$ order originating from main branch 2 (in $20 \%$ of the cases). The latter type of ramification, representing the majority of cases, was included in a graphical representation of a proposed basic pattern of ramification (Fig. 3).

The superimposed sketches of the six main branches (Fig. 2) showed that every main branch was encountered in a typical, limited space on the neopallium's surface (region of residence): main branches 1,3 and 5 covered a region of residence that was approximately the width of two fingers, whereas the positions of main branches 2, 4 and 6 varied within a region of up to the width of three fingers.

The averaged calibre of the MCA was $2.35 \mathrm{~mm}$ (2.00-2.75 mm). All main branches originating from it had an averaged calibre of 1.00-1.5 mm (1.16$-1.42 \mathrm{~mm}$ ); main branch 4 was the widest ( $1.42 \mathrm{~mm}$ ).

\section{Origin and ramification of CA}

The left and right CA originated from an impaired, common trunk that resulted from the confluence of the left and right RCA in the median plane of the brain's ventral side. In one case only, the left RCA was absent so that the CAC was not closed rostrally. Hence, the aforementioned common trunk in the median plane was simply a continuation of the right RCA. The common trunk entered the space between the left and right cerebral hemisphere (fissura longitudinalis cerebri) and continued along the dorsal surface of the rostrum and genu corporis callosi.

Seven main branches originated from the CA (Figs. 4, 5). Main branch 5 was the only one found in all specimens; main branch 2 was present in 16 of 17 brains. Main branches 3 and 4 were the most variable, being present in only 10 of 17 brains.

The CA always terminated by forming a bifurcation; this was located vaguely at the transition of the genu corporis callosi into the truncus corporis callosi (or slightly caudal to that site). Main branch 5 (in $65 \%$ of the brains) and main branch 6 (in 58\% of the brains) were the arms of this bifurcation (Fig. 5).

In the majority of specimens, main branches 2 to 6 were predominantly given off directly from the CA. The main branch 7 , however, was a branch of $2^{\text {nd }}$ order originating from main branch 6 in $55 \%$ of the brains.

Main branch 1 was extremely variable: it originated either from the CA (or from the CA's common trunk) or from the main branch 2 (in the latter case being a branch of $2^{\text {nd }}$ order); in one case, it originated (as a branch of $2^{\text {nd }}$ order) from main branch 3 . Respecting this variability and the lack of a clearly dominating type of ramification, both types ( $1^{\text {st }}$ order origin from CA and $2^{\text {nd }}$ order origin from main branch 2) were integrated into the sketch of the basic ramification pattern (Fig. 5).

Main branch 3 was extremely variable too: plenty of alternative origins from either main branch 1, 2, 3 or 5 occurred - all of $2^{\text {nd }}$ order (Fig. 4). However, in a slight majority of cases $(40 \%)$, its $1^{\text {st }}$ order origin - directly from the CA - was encountered. 


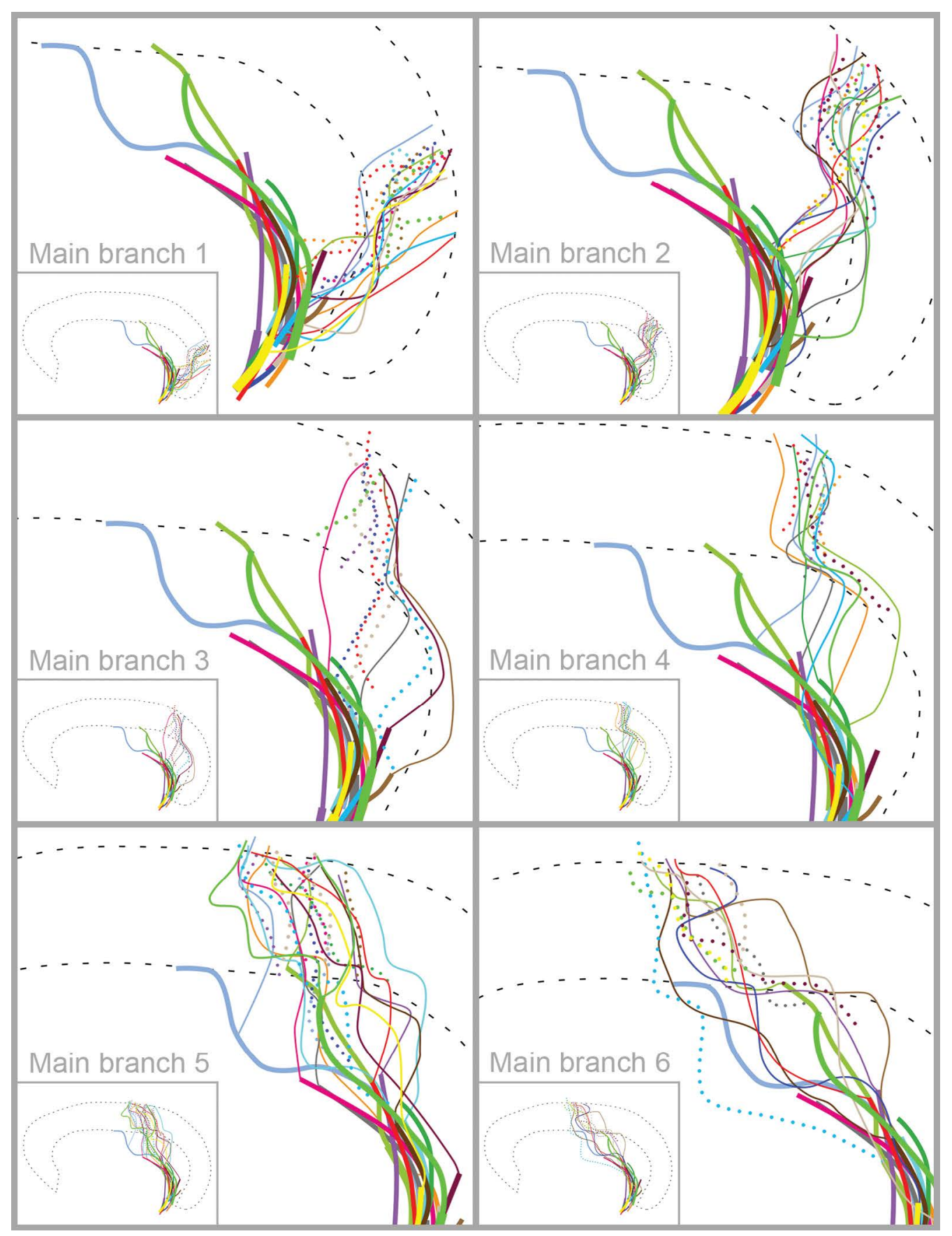

Figure 4. Graphical representations of the A. corporis callosi (CA; thick lines), and six of its seven main branches (for main branch 7 see Figure 5, left sketch). The comparative survey is facilitated by means of superimposition of the 17 sketches from the 17 equine brains (colour-coded). The main branches were of $1^{\text {st }}$ order (thin lines) or of $2^{\text {nd }}$ order (dotted lines). Medial view ( $90^{\circ}$ perspective); the neopallium is delineated by a mean contour (dashed line). Each of the main branches spread over its typical region of residence.

Accordingly, this type of ramification was included in the sketch of a proposed basic pattern of ramification (Fig. 5) of the CA.

All main branches took a dorsal or caudodorsal course. Firstly, they entered the sulcus genualis, i.e., the long primary sulcus that continued into the sulcus cinguli and the sulcus splenialis in a caudal direction, which all delineated the medial border of the neopallium. Then, the main branches, subsequently originating from the CA, ran almost vertically towards and across the neopallium's Margo rostralis and Margo dorsalis ("Mantelkante"). Accordingly, these main branches of the CA also reached regions on the lateral surface of the neopallium (Facies convexa), i.e., the rostrodorsal sectors $\mathrm{X}, \mathrm{IV}$ and $\mathrm{V}$ and the dorsal sectors XI and XIV. 


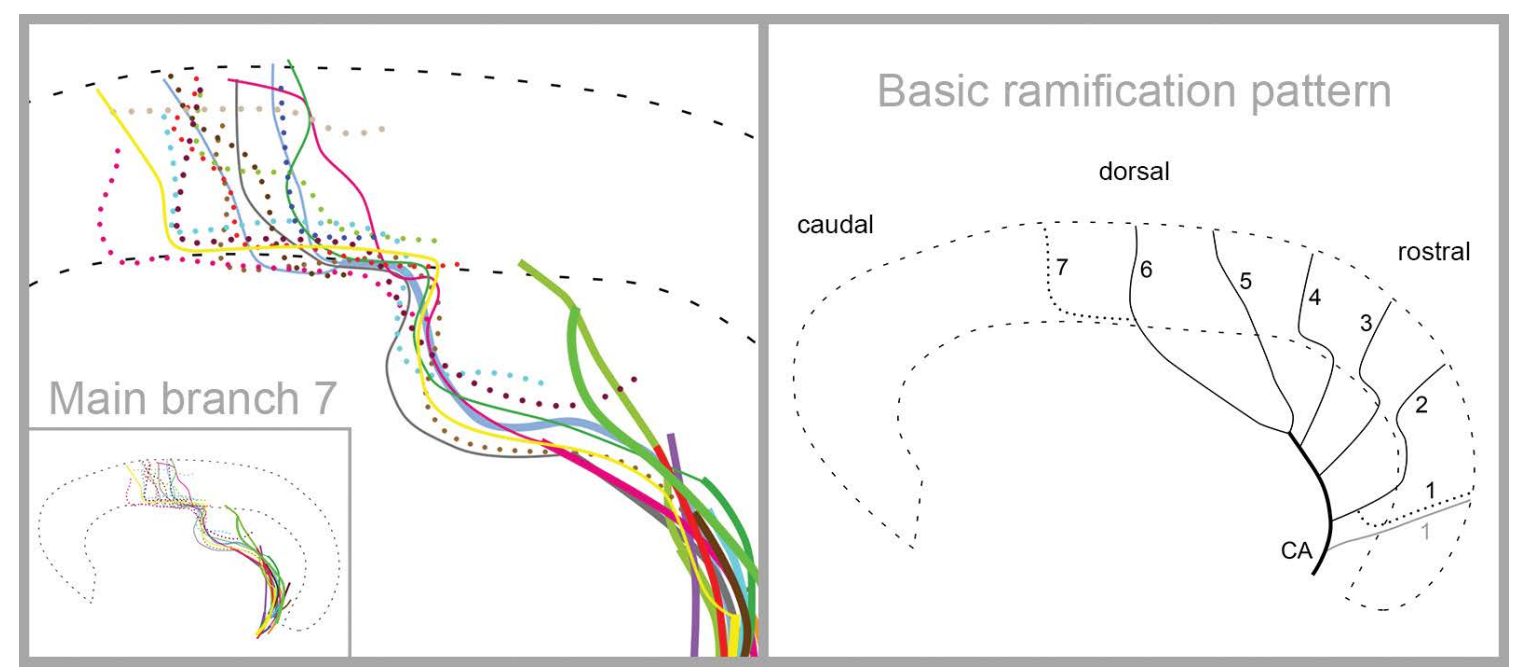

Figure 5. Left side: Graphical representation of the A. corporis callosi (CA; thick lines) and its main branch 7. Like in Figure 4, the 17 sketches from the 17 equine brains (colour-coded) were superimposed. The main branch 7 was either of $1^{\text {st }}$ order (thin lines) or of $2^{\text {nd }}$ order (dotted lines). Medial view $\left(90^{\circ}\right.$ perspective); the neopallium is delineated by a mean contour (dashed line). Right side: Sketch of a proposed basic pattern of ramification of the CA into seven main branches, which were of $1^{\text {st }}$ order (thin lines) or of $2^{\text {nd }}$ order (dotted lines). As for main branch 1, no clear preference of either $1^{\text {st }}$ or $2^{\text {nd }}$ order type could be identified (both variations are displayed). Similarly, main branch 3 varied markedly too, but a slight majority of the $1^{\text {st }}$ order type gave reason to prefer this type in this sketch (the other variations, as mentioned in the text, must be kept in mind). Note the bifurcation into main branches 5 and 6 . Meandering courses are not displayed; approximate position on the neopallium according to Figure 4. Medial view; dashed line - mean contour of the neopallium.

The position of main branch 4 on the neopallium varied only slightly, meaning that its region of residence was relatively narrow (Fig. 4). In contrast, the regions of residence of the other main branches (Figs. 4,5 ) were wider, i.e., up to the width of three fingers.

The averaged calibre of the CA was $1.93 \mathrm{~mm}$ $(1.50-2.25 \mathrm{~mm})$, while all main branches had an averaged calibre of approximately $1 \mathrm{~mm}(0.89-1.16 \mathrm{~mm})$.

\section{Supply areas of MCA}

The main branches of the MCA spread over a region that represented the largest portion of the Facies convexa (i.e., sectors I to XV). However, they reached neither the rostral pole nor the caudal pole of the neopallium (Fig. 6). Every main branch was topographically related to more than one sector, and, in general, each of the 15 sectors was supplied by more than one main branch of MCA (except sector X; Table 1). Often, some main branches lay in certain sulci, but they never continued all the way exclusively inside them; instead, many main branches were seen to cross the gyri without following the course of a sulcus.

Main branch 1 often ran either in the sulcus suprasylvius or in the sulcus diagonalis. Accordingly, it was predominantly related to sector III and to the rostral third of sector $I$, as well as to a small ventral portion of sector IX (Fig. 6; Table 1). It also continued dorsally to reach sector IV.
Main branch 2 usually entered the sulcus diagonalis located between sectors I and III. In all brains, it reached sector IV (Fig. 6; Table 1). Sometimes, it took a slightly caudal course into the laterodorsal sector $\mathrm{V}$.

Main branch 3 frequently ran along the Fissura sylvia and was primarily associated with sectors I, IV and V (Table 1; Fig. 6). Occasionally, it entered sector XI (in 62\% of the cases) on the dorsal surface of the neopallium.

Main branch 4 was initially located in the Fissura sylvia (between sectors I and II). In its further course in a caudodorsal direction; however, it crossed sector VI and reached the dorsal sector XII that lay dorsal to the sulcus suprasylvius (Table 1; Fig. 6). Often, it even crossed the sulcus ectomarginalis and contributed to the vascular supply of sector XIV, too.

Main branch 5 was one of the dominant vascular branches in sector II (present here in $92 \%$ of the brains). On its way in a caudodorsal direction, it passed through sectors VII and VIII (Table 1; Fig. 6). It often followed the course of the sulcus obliquus towards its intersection with the sulcus suprasylvius.

Main branch 6 was finally encountered in sector VII, in the two rostral thirds of sector VIII and in a small rostral portion of sector XIII (Table 1; Fig. 6).

\section{Supply areas of CA}

Initially ramifying from the CA on the medial side of the brain's hemisphere, some of the main branches 


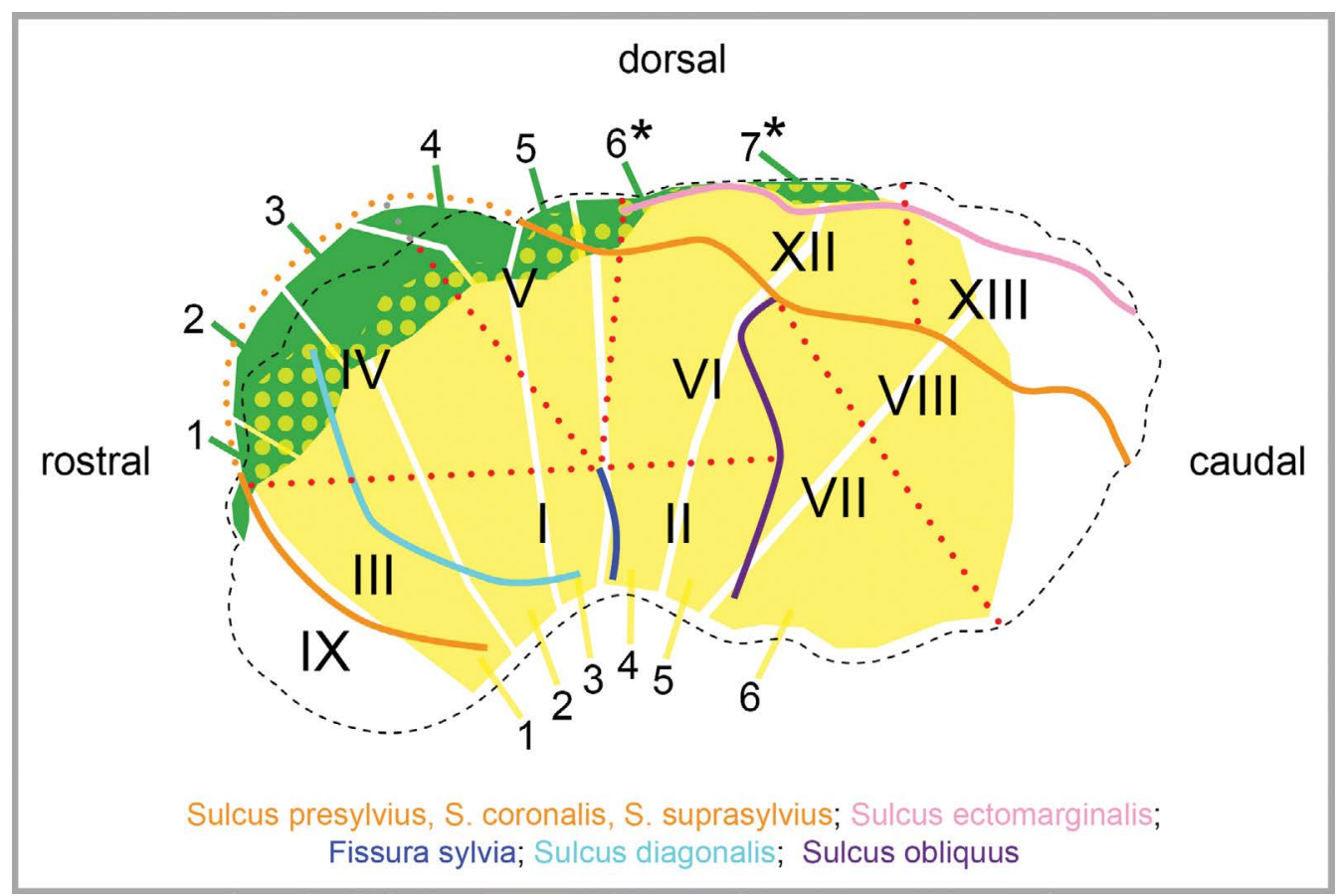

Figure 6. Graphical representation of the averaged supply areas of main branches 1 to 6 of the A. cerebri media (MCA; yellow) and main branches 1 to 7 of the A. corporis callosi (CA; green) on the Facies convexa of the equine brain. Lateral view $\left(90^{\circ}\right.$ perspective). The colour-coded primary sulci [21] and the auxiliary lines (red dotted) mark the boundaries of the sectors (asterisks indicate dorsal sectors invisible in the lateral view; compare Figure 1). Note the multiple-supply situation (sectors shaded with two colours, i.e. yellow and green [e.g., sector IV]) facilitated by main branches from both MCA and CA.

Table 1. Survey on the presence of main branches 1-6 of the A. cerebri media (MCA) in the 15 sectors (I-XV) of the neopallium's Facies convexa in 17 equine brains

\begin{tabular}{|c|c|c|c|c|c|c|}
\hline \multirow[t]{2}{*}{ Sector } & \multicolumn{6}{|c|}{ Main branches of MCA } \\
\hline & $1(n=13)$ & $2(n=17)$ & $3(n=13)$ & $4(n=17)$ & $5(n=15)$ & $6(n=17)$ \\
\hline I & $62 \%$ & $88 \%$ & $100 \%$ & $71 \%$ & * & - \\
\hline$\|$ & - & $*$ & $46 \%$ & $88 \%$ & $93 \%$ & $65 \%$ \\
\hline III & $100 \%$ & $88 \%$ & $31 \%$ & $*$ & - & - \\
\hline IV & $77 \%$ & $100 \%$ & $77 \%$ & * & * & - \\
\hline V & - & $53 \%$ & $100 \%$ & $53 \%$ & * & * \\
\hline $\mathrm{Vl}$ & - & - & * & $88 \%$ & $73 \%$ & * \\
\hline VII & - & - & - & - & $87 \%$ & $100 \%$ \\
\hline VIII & - & - & - & - & $67 \%$ & $88 \%$ \\
\hline IX & $69 \%$ & * & - & - & - & - \\
\hline$x$ & $31 \%$ & - & - & - & - & - \\
\hline$X I$ & - & * & $62 \%$ & $59 \%$ & * & * \\
\hline XII & - & - & * & $88 \%$ & $80 \%$ & * \\
\hline XIII & - & - & - & * & $67 \%$ & $59 \%$ \\
\hline XIV & - & - & * & $88 \%$ & $53 \%$ & * \\
\hline$X V$ & - & - & - & * & $47 \%$ & * \\
\hline
\end{tabular}

$100 \%$ - a main branch was encountered in the respective sector in all of the brains: *Values below $25 \%$ are not listed. Whenever a main branch ran along the boundary between two sectors (e.g., in a sulcus), it was supposed to supply each of the two neighbouring sectors and, therefore, was counted for both sectors individually. The number of samples (n) was smaller than 17 when the respective main branch was not found in the specimen 
Table 2. Survey on the presence of main branches 1-7 of the A. corporis callosi (CA) in the 15 sectors (I-XV) of the neopallium's Facies convexa in 17 equine brains

\begin{tabular}{|c|c|c|c|c|c|c|c|}
\hline \multirow[t]{2}{*}{ Sector } & \multicolumn{7}{|c|}{ Main branches of CA } \\
\hline & $1(n=14)$ & $2(n=16)$ & $3(n=10)$ & $4(n=11)$ & $5(n=17)$ & $6(n=12)$ & $7(n=13)$ \\
\hline IV & $29 \%$ & $88 \%$ & $80 \%$ & $27 \%$ & - & - & - \\
\hline V & - & * & $30 \%$ & $82 \%$ & $59 \%$ & - & - \\
\hline IX & $86 \%$ & * & - & - & - & - & - \\
\hline$x$ & $50 \%$ & $100 \%$ & $90 \%$ & $73 \%$ & - & - & - \\
\hline$X I$ & - & - & $30 \%$ & $100 \%$ & $100 \%$ & $75 \%$ & * \\
\hline XII & - & - & - & - & $*$ & - & - \\
\hline XIV & - & - & - & - & $*$ & $100 \%$ & $77 \%$ \\
\hline XV & - & - & - & - & - & - & * \\
\hline
\end{tabular}

$100 \%$ - a main branch was encountered in the respective sector in all of the brains; *Values below $25 \%$ are not listed. Whenever a main branch ran along the boundary between two sectors (e.g., in a sulcus), it was supposed to supply each of the two neighbouring sectors and, therefore, was counted for both sectors individually. The number of samples (n) was smaller than 17 when the respective main branch was not found in the specimen

ran across the neopallium's Margo dorsalis ("Mantelkante") to continue on the lateral side, i.e., on the Facies convexa. In this way, they entered the rostrodorsal and dorsal sectors X, XI and XIV and parts of sectors IV and V (Table 2; Fig. 6).

Consequently, each of these sectors was supplied by both cerebral stem arteries, i.e., MCA and CA (instead of only one of these) in terms of a so-called multiple-supply situation (Fig. 6; compare Tables 1 and 2).

\section{DISCUSSION \\ Origin of MCA and CA}

In 16 of the 17 specimens, the MCA originated from the RCA in accordance with the common pattern $[1,5,25]$.

The CA always originated from a common, impaired trunk, as had been reported earlier [1, 11, 24]. Despite this anatomical evidence, the nomenclature is different in the related literature. Being formed by the confluence of the right and left RCA (rostrolateral portion of the $(A C)$, this common trunk was designated as the azygos anterior cerebral artery [11] or as the A. communicans rostralis [1]. Finally, other authors [5] described this trunk as being one of the three segments of the RCA, meaning that the right and left RCA formed the rostrolateral portion of the CAC (first segment); then the right and left RCA joined to form the $A$. communicans rostralis (second segment, representing the impaired trunk); and finally, the trunk rostrally bifurcated into a left and right artery (third segment); the latter continued in a caudodorsal direction on the medial surface of each hemisphere without being given another name.

Hence, the term CA is not used at all in that context $[5,25]$. In fact, it is not listed in the Nomina Anatomica Veterinaria [25] either. However, the term CA is used in current research articles $[11,18,24]$ and textbooks [e.g. 1]. Considering the regular presence of these arteries in all 17 specimens in this study, and appreciating the descriptive value for topographical reasons, the present study gives substantial reason to add the terms $A$. cerebri rostralis impar (azygos anterior cerebral artery of [11]) and A. corporis callosi (or preferably, as in human anatomy, A. pericallosa instead of A. corporis callosi) to the Nomina Anatomica Veterinaria.

\section{Ramification pattern of MCA}

In human anatomy, the arterial branches of the MCA are named according to the sulci in which they usually occur, like for example, A. sulci centralis [7] that runs along the sulcus centralis. This concept appears to not be applicable to the horse: Firstly, the equine neopallium shows a very complex gyration pattern [21, 23] and, secondly, the arterial branches did not regularly run along the sulci, but often took a course across the gyri [2].

\section{Supply areas of MCA and CA}

The topographical analysis clearly revealed that the rostral pole and the caudal pole of the neopallium were always void of main branches from MCA and CA. The applied cartographic system of sectors was 
a valuable tool to delineate these sites in appropriate detail (i.e., sector IX at the rostral pole, and the caudal parts of sectors VIII, XIII and XV at the caudal pole). Instead, these sectors were supplied via branches from the A. ethmoidalis externa (rostral pole, sector IX) and by branches of the $A$. cerebri caudalis (caudal pole, sectors VIII, XIII and XV), respectively, as previously described [2].

The widest part of the Facies convexa, however, was vascularised by the six main branches of MCA, each of them attributed to its special region of residence represented by the respective sectors of the cartographic system. It must be emphasized that every sector was always reached by more than one main branch, except sector X. Clearly, the rostrodorsal and dorsal portion of the Facies convexa, represented by sectors IV, V, X, XI and XIV, received an additional supply from the hemisphere's medial side, as main branches from the CA extended across the Margo rostralis and Margo dorsalis and - together with main branches from the MCA - contributed to a so-called multiple-supply situation. Furthermore, it must be pointed out that in sector $X$, branches from the CA compensated for the little supply contributed by branches from the MCA. In functional terms, considering early electrophysiological experiments [4] and histological data $[6,15]$, some of these special sectors (IV, V, X, XI) were particularly discussed $[2,12]$ with regard to the suggested position of the area motorica of the equine brain.

Additionally, the present study elucidates that it was the $C A$, which mainly contributed to supplying the larger parts of the respective sectors (IV, $\mathrm{V}, \mathrm{X}, \mathrm{XI}$ ) within this motor area. Its branches were protected in the deep gap between the heimspheres as they proceeded from the interhemispheric fissura longitudinalis cerebri. Clinically, this feature may be regarded as some sort of a safety mechanism in cases of lateral cranial and brain trauma. Traumatic head injuries are common in horses $[9,10,14,16,22]$. In general, such traumatic insults may require surgical procedures [19]; knowledge of the special regions of residence where the typical main branches of the cerebral stem arteries were located may be helpful in terms of treatment and prognosis of the injury.

\section{CONCLUSIONS}

Transferring the vascular ramification patterns and regions of residence into the cartographic system of the neocortical sectors facilitated the detailed description of characteristic vascular supply areas on the Facies convexa of the equine neopallium. This combination of two topographical procedures offered substantial advantages; firstly, to adequately observe the horse's complex and apparently complicated gyration pattern, and, secondly, to overcome immanent orientation problems by implementing a procedure that is reproducibly standardised.

\section{Acknowledgements}

We most gratefully acknowledge the expert contribution of our native speaker, Ms. Frances Sherwood-Brock, who meticulously revised the English manuscript.

\section{REFERENCES}

1. Böhme G. (ed.). Nickel R, Schummer A, Seiferle E. Lehrbuch der Anatomie der Haustiere, Bd. IV: Nervensystem, Sinnesorgane, Endokrine Drüsen (4th ed.). Parey, Stuttgart, Germany 2004.

2. Böing L. Die arterielle Vaskularisation der Gehirnoberfläche beim adulten Warmblutpferd: Anatomische Untersuchung unter Berücksichtigung des tierartspezifischen Furchungsmusters des Neopalliums (doctoral dissertation, submitted). University of Veterinary Medicine, Hannover 2020.

3. Böing L, Heun $F$, Gasse $H$. The arterial ramification pattern of the horse's brain with regard to topographical sectors of the neopallium (Poster 79). 114th Annual Meeting, Anatomische Gesellschaft, Würzburg 2019.

4. Breazile JE, Swafford BC, Biles DR. Motor cortex of the horse. Am J Vet Res. 1966; 27(121): 1605-1609, indexed in Pubmed: 5971615.

5. Constantinescu GM. Illustrated Veterinary Anatomical Nomenclature (4th ed.). Thieme, Stuttgart, Germany 2018.

6. Cozzi B, De Giorgio A, Peruffo A, et al. The laminar organization of the motor cortex in monodactylous mammals: a comparative assessment based on horse, chimpanzee, and macaque. Brain Struct Funct. 2017; 222(6): 2743-2757, doi: 10.1007/s00429-017-1369-3, indexed in Pubmed: 28210850.

7. Deller T. Hirngefäße. In: Waschke J, Böckers TM, Paulsen F. Anatomie. Das Lehrbuch. Sobotta (ISBN 978-3-437-44080-9). Urban-Fischer (in Elsevier), München, Germany 2015: 623-644.

8. Dexler H. Beiträge zur Kenntnis des feineren Baues des Zentralnervensystems der Ungulaten. Gegenbaurs Morphologisches Jahrbuch. 1904; 32: 288-389.

9. Feary DJ. Review of the management of traumatic brain injury in horses. AAEP Proceedings. 2007; 53: 519-524.

10. Fürst $A$, Jackson $M$, Kümmerle J, et al. Summary of current therapeutic measurements in head fractures of horses. Pferdeheilkunde Equine Medicine. 2010; 26(4): 503-514, doi: 10.21836/pem20100403.

11. Gillan LA. Blood supply to brains of ungulates with and without a rete mirabile caroticum. J Comp Neurol. 1974; 153(3): 275-290, doi: 10.1002/cne.901530305, indexed in Pubmed: 4817350 
12. Heun F. Morphometrische Untersuchung der topographischen Beziehungen zwischen externen Landmarks am Kopf und kartographischen Mustern des Neopalliums bei adulten Warmblutpferden (doctoral dissertation, submitted). University of Veterinary Medicine, Hannover 2020.

13. Heun F, Böing L, Gasse H. A stereotactic approach for a topographical mapping of the neopallium in the horse (Poster 80). 114th Annual Meeting, Anatomische Gesellschaft, Würzburg 2019.

14. Hug S. Epidemiologische Untersuchungen der Frakturpatienten der Pferdeklinik - Bedeutung der Schlagverletzung als Ursache von Frakturen (doctoral dissertation). University of Zurich, Vetsuisse Faculty 2009.

15. Hummel G. Die Feinstruktur der motorischen Großhirnrinde des Pf erdes. J Vet Med C. 1976; 5: 35-53, doi: 10.1111/j.1439-0264.1976.tb00655.x.

16. Hurcombe S. Traumatic head injury in horses. Proceedings of the NAVC Conference. 2010; 24: 146-149.

17. Jenke W. Die Gehirnarterien des Pferdes, Hundes, Rindes und Schweines verglichen mit denen des Menschen (doctoral dissertation). University of Veterinary Medicine, Dresden 1919.

18. Jerbi $H$, Vazquez N, Pérez W. Morphological configuration and topography of the brain arterial supply of the onehumped camel (Camelus dromedarius, linnaeus 1758). Int J Morphol. 2019; 37(3): 1095-1100, doi: 10.4067/ s0717-95022019000301095.

19. Kramer J, Coates JR, Hoffman AG, et al. Preliminary anatomic investigation of three approaches to the equine cranium and brain for limited craniectomy procedures. Vet Surg. 2007; 36(5): 500-508, doi: 10.1111/j.1532950X.2007.00297.x, indexed in Pubmed: 17614932.

20. Lang A, Sherwood-Brock F, Gasse H. Hermann Dexler's "Beiträge zur Kenntnis des feineren Baues des Zentralnervensystems der Ungulaten." An Annotated English Translation of the Original German Article; Part V: Telencephalon - Adult Stages. University of Veterinary Medicine Hannover. 2018, doi: 10.15487/TiHo.4_2018.1/5.

21. Lang A, Wirth G, Gasse H. Review of the surface architecture of the equine neopallium: Principle elements of a cartographic pattern of sulci revisited and further elaborated. Anat Histol Embryol. 2018; 47(4): 280-297, doi: 10.1111/ahe.12355, indexed in Pubmed: 29542168.

22. Müller JM, Hellige M, Hoffmann MV, et al. Parietal cerebral defect after skull fracture as a cause of posttraumatic epilepsy in an Icelandic horse. Pferdeheilkunde Equine Medicine. 2011; 27(3): 306-310, doi: 10.21836/pem20110317.

23. Pillay P, Manger PR. Order-specific quantitative patterns of cortical gyrification. Eur J Neurosci. 2007; 25(9): 2705-2712, doi: 10.1111/j.1460-9568.2007.05524.x, indexed in Pubmed: 17459107.

24. Rösslein C. Angioarchitektonische Untersuchungen an den Arterien des Encephalon und der Meninges beim Pferd (doctoral dissertation). Veterinary Faculty of Ludwig-Maximilians-Universität, München 1987.

25. World Association of Veterinary Anatomists. Nomina Anatomica Veterinaria, N.A.V. (6th ed.), 2017. http://www. wava-amav.org. 